\title{
Analisis Pengaruh Tata Kelola Perusahaan Terhadap Pengungkapan Sukarela pada Perusahaan Keluarga
}

\author{
Ivone \\ Universitas Internasional Batam \\ ivone@uib.edu \\ Budi Chandra \\ Universitas Internasional Batam \\ budi.chandra@uib.ac.id
}

\begin{abstract}
Abstrak
Bisnis keluarga berkembang pesat dan menjadi bisnis yang dominan di Indonesia. Semakin penting bisnis keluarga pada perekonomian Indonesia menjadikan bisnis keluarga menjadi sorotan di dunia ekonomi. Pada perusahaan keluarga terdapat keunikan dimana mayoritas kepemilikan saham dimiliki oleh anggota keluarga, sehingga dapat menyebabkan konflik keagenan yang mengurangi transparansi dalam pengungkapan informasi. Penelitian ini bertujuan meneliti pengaruh tata kelola perusahaan terhadap pengungkapan sukarela pada perusahaan keluarga. Variabel tata kelola perusahaan yang digunakan dalam penelitian adalah kepemilikan institusional, kepemilikan asing, kepemilikan manajerial, ukuran dewan, komisaris independen, dan audit komite. Sampel dari penelitian ini menggunakan 125 perusahaan keluarga yang terdaftar di Bursa Efek Indonesia pada periode 20102014 yang dipilih dengan menggunakan metode purposive sampling. Penelitian ini diolah menggunakan program Eviews 7 serta Statistical Package for the Social Sciences (SPSS) 21. Data yang digunakan dalam penelitian ini adalah laporan tahunan dari setiap perusahaan yang dipublikasikan (www.idx.co.id). Data yang telah diperoleh akan diuji dengan pengujian regresi panel. Dari hasil penelitian ditemukan bahwa pada perusahaan keluarga, kepemilikan selain keluarga seperti kepemilikan institusional, kepemilikan asing dan kepemilikan manajerial tidak berpengaruh signifikan terhadap pengungkapan sukarela. Ukuran dewan, komite audit, ukuran perusahaan, dan profitabilitas memiliki pengaruh signifikan positif terhadap pengungkapan sukarela. Komisaris independent dan leverage tidak memiliki pengaruh signifikan terhadap pengungkapan sukarela. Kesimpulan dapat ditarik bahwa dalam perusahaan keluarga, kepemilikan selain kepemilikan keluarga tidak memiliki pengaruh signifikan terhadap pengungkapan informasi secara sukarela.
\end{abstract}

Kata Kunci Perusahaan Keluarga, Tata Kelola Perusahaan, Pengungkapan Sukarela 


\section{PENDAHULUAN}

Bisnis keluarga di Indonesia telah berkembang pesat dan menjadi bisnis yang dominan di Indonesia. Pada tahun 2014, survei yang telah dilakukan oleh sebuah perusahaan auditor ternama di dunia yakni PricewaterhouseCoopers, bisnis keluarga merupakan 95\% dari seluruh bisnis yang ada di Indonesia. Kegiatan bisnis keluarga telah memberikan kontribusi besar terhadap ekonomi Indonesia. Perusahaan keluarga memegang peran penting dalam istilah generasi tenaga kerja dan perkembangan ekonomi (Louie, Ahmed, \& Ji, 2019).

Perusahaan keluarga adalah perusahaan dimana anggota dari keluarga perintis perusahaan akan berkelanjutan dalam memegang jabatan tinggi dalam manajemen perusahaan, seperti pada posisi direktur atau pemegang saham. Perusahaan keluarga memiliki karakteristik struktur kepemilikan yang berbeda dengan perusahaan lain. Dengan struktur kepemilikan unik serta konflik keagenan yang dimiliki oleh perusahaan keluarga berpotensi membedakan perilaku bisnis dengan perusahaan non-keluarga (Huang \& Kang, 2019).

Pengungkapan informasi secara transparan oleh perusahaan menandakan perusahaan memiliki efisiensi yang baik. Perusahaan dapat memberikan pengungkapan melalui laporan tahunan baik melalui pengungkapan wajib maupun pengungkapan sukarela. Pengungkapan wajib adalah pengungkapan informasi oleh perusahaan sesuai batas pengungkapan minimum yang telah ditetapkan. Pengungkapan sukarela adalah pengungkapan informasi selain daripada laporan keuangan yang tidak secara eksplisit diperlukan oleh standar akuntasi yang berlaku (FASB, 2000).

Pengungkapan informasi menjadi tidak optimal disebabkan adanya perbedaan kepentingan antara manajemen dan pemegang saham (Jensen dan Meckling, 1976). Dengan informasi lebih yang dimiliki manajemen, pihak manajemen yang memegang oportunisme cenderung tidak mengungkapkan beberapa informasi yang penting bagi pemegang saham. Konflik keagenan tidak hanya terjadi antara manajemen dan pemegang saham tetapi terdapat konflik yang terjadi juga pada perusahaan yang memiliki struktur kepemilikan terkonsentrasi, dimana pemegang saham pengendali mengontrol tindakan perusahaan.

Pengungkapan sukarela menunjukkan tingkat transparansi yang tinggi sehingga dapat menunjukkan mekanisme tata kelola perusahaan yang maksimal pada perusahaan. Pada perusahaan keluarga, pemegang saham dan manajemen dominan adalah anggota keluarga pendiri perusahaan (Darmadi \& Sodikin, 2013). Pada saat saham kepemilikan meningkat hingga titik tertentu, perusahaan akan mengalami konflik keagenan yang berbeda dimana kepemilikan dominan berpotensi melakukan transaksi tidak wajar yang dapat merugikan investor publik (Louie, Ahmed, \& Ji, 2019)

Tata kelola perusahaan berperan penting dalam mengurangi konflik keagenan termasuk mendorong perusahaan semakin transparan dalam pengungkapan informasi (Chen \& Jaggi, 2000). Dengan adanya tata kelola perusahaan, perusahaan akan mengungkapkan informasi selengkapnya agar tidak terdapat informasi asimetris antara manajemen dan pemegang saham maupun pemegang saham mayoritas dan minoritas. Mekanisme tata kelola adalah mekanisme pengawasan secara internal/eksternal seperti struktur kepemilikan, karakteristik dewan, dan karakteristik komite audit. Di Indonesia, dimana terdapat struktur kepemilikan terkonsentasi yang lebih dominan, maka diprediksi bahwa tata kelola perusahaan akan berkontribusi mengurangi informasi asimetris serta meningkatkan pengungkapan informasi (Darmadi \& Sodikin, 2013). 
Peranan perusahaan keluarga pada perusahaan di Indonesia menjadi sangat penting pada sekarang ini disebabkan atas jumlah perusahaan keluarga yang dominan dari seluruh perusahaan di Indonesia. Dibandingkan dengan negara di Asia Timur, perusahaan publik Indonesia menunjukkan tingkat kepemilikan keluarga yang lebih tinggi serta terkonsentrasi (Claessens et al., 2000). Berdasarkan survei yang dilakukan oleh PricewaterhouseCoopers (PWC) mengenai bisnis keluarga di Indonesia pada tahun 2014 menyatakan bahwa Indonesia diprediksikan sebagai kekuatan ekonomi terbesar ke-4 di dunia pada 2050. Penelitian ini akan fokus pada perusahaan-perusahaan publik di Indonesia.

\section{LANDASAN TEORI \\ 1. Pengungkapan Sukarela}

Pengungkapan sukarela berperan sebagai mekanisme tata kelola eksternal dalam memonitor manajemen untuk mengurangi biaya agensi. Pengungkapan sukarela dapat mengurangi selisih informasi antara pemilik mayoritas dengan pemilik minoritas yang tidak mendapatkan informasi lengkap (Louie, Ahmed, \& Ji, 2019). Pengungkapan informasi berdasarkan hubungan persyaratan terdiri dari dua jenis pengungkapan, yakni pengungkapan wajib (mandatory disclosure) dan pengungkapan sukarela (voluntary disclosure). Pengungkapan wajib adalah pengungkapan minimum yang telah disyaratkan oleh lembaga berwenang.

Pengungkapan wajib di Indonesia diatur oleh BAPEPAM melalui Keputusan Ketua BAPEPAM dan Lembaga Keuangan No. KEP-431/BL/2012 peraturan X.K.6 tanggal 1 Agustus 2012 tentang penyampaian laporan tahunan emiten atau perusahaan publik.

\section{Perusahaan Keluarga}

Perusahaan keluarga adalah perusahaan dimana anggota keluarga dari keluarga pemilik terus menjabat posisi direksi atau pemegang saham dominan. Pemisahan manajemen dari kendali kepemilikan jarang terjadi dalam perusahaan yang sahamnya terkonsentrasi pada pemilik keluarga. Menurut Vural (2018), keberadaan keluarga dalam manajemen perusahaan serta keuntungan dalam mendapatkan informasi perusahaan menyebabkan kepemilikan keluarga menjadi dominan dalam pengungkapan informasi.

Pada perusahaan keluarga terdapat pengawasan yang baik dari pihak manajemen yang merupakan pemegang saham pengendali, menyebabkan permintaan informasi untuk pemegang saham minoritas menjadi kecil (Bushman et al., 2004). Hal tersebut menandakan perusahaan keluarga memilih pengungkapan sukarela yang lebih sedikit. Pemilik keluarga yang menjabat sebagai direksi atau pemegang saham pengendali akan terpengaruh akan keputusan perusahaan, mereka dapat mengarahkan pengungkapan perusahaan sesuai kepentingan mereka pribadi.

Akan tetapi, pada perusahaan keluarga kepemilikan terkonsentrasi dan tidak beragam, dengan struktur kepemilikan seperti itu perusahaan cenderung melakukan pengungkapan sukarela kurang dari pada perusahaan lain. Seperti yang dibahas di atas, bahwa tidak terdapat penjelasan apakah kepemilikan keluarga memilih pengungkapan informasi maksimal atau tidak. 


\section{Tata Kelola Perusahaan dan Pengungkapan Sukarela}

Seiring sejumlah perusahaan bangkrut pada awal tahun 2000 pada negara maju dan berkembang, peneliti mulai tertarik untuk meneliti mekanisme tata kelola perusahaan dan kontribusinya terhadap perusahaan (Zanani et al., 2008). Mekanisme tata kelola perusahaan menyediakan struktur pengendalian internal yang dapat mengurangi konflik keagenan di perusahaan. Dengan adanya lingkungan pengawasan insentif maka sikap oportunis manajemen, informasi asimetri, dan keinginan untuk menyimpan informasi untuk kepentingan pribadi akan berkurang sehingga dapat meningkatkan pengungkapan informasi perusahaan (Ho \& Wong, 2001).

Dengan adanya transparansi dan akuntabilitas dalam pengungkapan informasi adalah kunci penting dalam mekanisme tata kelola perusahaan. Perusahaan dapat dengan mudah meningkatkan modal jika perusahaan memiliki reputasi baik atas pelaporan finansial. Levitt (2000) mengatakan bahwa tata kelola perusahan yang baik berpengaruh terhadap pelaporan finansial perusahaan dan meningkatkan kepercayaan investor. Pengungkapan sukarela melengkapi pengungkapan secara keseluruhan yang dapat meningkatkan proses pengungkapan finansial (Wang \& Zezhen, 2011).

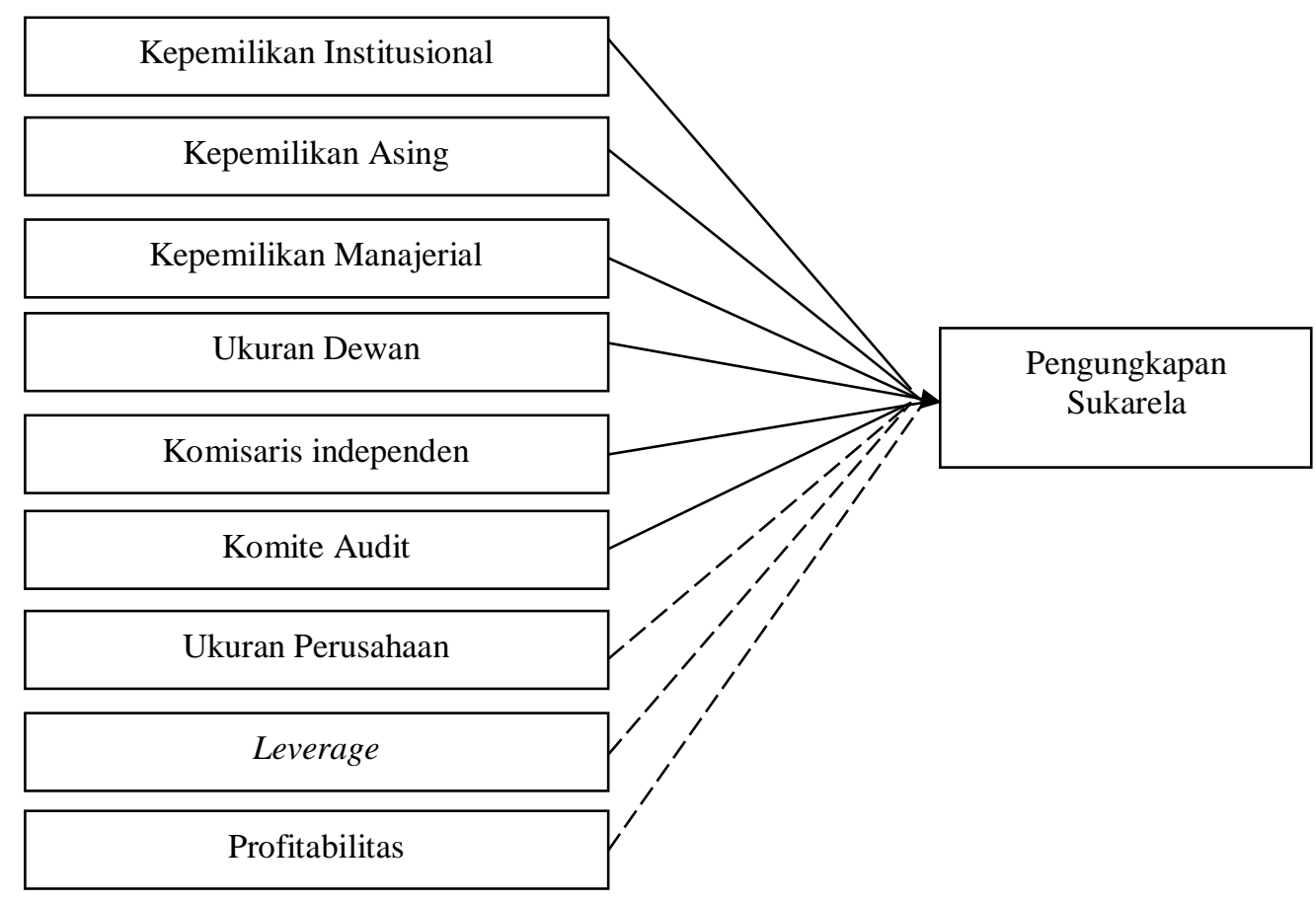

Gambar 1. Model penelitian analisis pengaruh tata kelola perusahaan terhadap pengungkapan sukarela pada perusahaan keluarga

\section{METODOLOGI PENELITIAN}

Penelitian ini termasuk dalam penelitian dasar apabila ditinjau dari tujuan penelitian, dimana model penelitian dikembangkan dan dievaluasi dari model penelitian terdahulu. Perkembangan model penelitian dilakukan dengan menguji hipotesis apakah variabel independen mempengaruhi variabel dependen secara signifikan. Penelitian ini bersifat kuantitatif yang menekankan pada pengujian teori melalui pengukuran terhadap variabel-variabel dengan angka dan melakukan analisis data menggunakan prosedur statistik (Indriantoro \& Supomo, 2013). 
Ditinjau dari karakteristik masalah, penelitian ini merupakan penelitian kausal komparatif dan penelitian historis. Penelitian kausal komparatif memiliki karakteristik berupa hubungan sebab-akibat antara dua variabel atau lebih. Penelitian historis memiliki karakteristik berupa data yang dijadikan objek penelitian adalah data perusahaan di masa lampau (Indriantoro \& Supomo, 2013).

Objek penelitian yang digunakan adalah perusahaan yang terdaftar di Bursa Efek Indonesia (BEI) selama periode tahun 2010-2014. Pengambilan sampel dilakukan dengan menggunakan metode purposive sampling. Sampel yang terpilih harus memenuhi beberapa kriteria sebagai berikut:

a. Perusahaan keluarga adalah perusahaan yang memenuhi kriteria kepemilikan keluarga berikut: (1) pihak keluarga memiliki minimum $20 \%$ saham dari perusahaan, (2) individu atau perusahaan pribadi (listed \& non-listed) mempunyai kepemilikan saham minimum 20\% dari perusahaan. Khusus perusahaan pribadi yang listed, maka telusuri perusahaan induknya atau kepemilikan terbesarnya apakah merupakan kepemilikan keluarga (Darmadi \& Sodikin, 2013).

b. Perusahaan non-keuangan dan non-BUMN tersebut telah terdaftar IPO selama lima tahun berturut-turut yang terhitung mulai tahun 2010-2014. Perusahaan keuangan dikeluarkan dari sampel penelitian disebabkan perusahaan keuangan memerlukan transparansi yang tinggi sehingga memiliki regulasi tata kelola perusahaan yang berbeda (Darmadi \& Sodikin, 2013). Perusahaan BUMN dikeluarkan sebab terdapat Surat Keputusan Menteri Badan Usaha Milik Negara No. KEP-117/M-MBU/2002 tentang Penerapan Good Corporate Governance pada BUMN sehingga berbeda dengan perusahaan pada umumnya.

c. Perusahaan yang memiliki data atau informasi keuangan untuk mengukur semua variabel pada penelitian ini yang diperoleh dari laporan keuangan dan laporan tahunan.

Variabel dependen pengungkapan sukarela menunjukkan jumlah informasi yang diungkapkan oleh perusahaan kepada pemegang saham dan publik. Pengungkapan sukarela diukur dengan cara menjumlahkan skor pengungkapan yang telah dibuat oleh Hossain dan Hammami (2009) sebanyak 44 item.

$$
\begin{aligned}
& \text { Pengungkapan } \\
& \text { Sukarela }
\end{aligned}=\frac{\sum \text { Pengungkapan Sukarela Perusahaan }}{\sum \text { Pengungkapan Sukarela yang diharapkan }}
$$

Keterangan:

$\Sigma$ Pengungkapan Sukarela Perusahaan $=$ jumlah skor dari item yang dibuat oleh Hossain dan Hammami (2009), jika perusahaan mengungkapkan item tersebut diberi nilai 1, dan 0 jika tidak.

Variabel independen pada penelitian ini merupakan kepemilikan institusional, kepemilikan asing, kepemilikan manajerial, ukuran dewan, komisaris independen, dan komite audit.

a. Kepemilikan institusional memiliki insentif kuat untuk mengawasi praktik pengungkapan informasi oleh perusahaan. Menurut Uyar et al. (2013), cara pengukuran kepemilikan institusional adalah sebagai berikut: 


$$
\begin{aligned}
& \text { Kepemilikan } \\
& \text { Institusional }
\end{aligned}=\frac{\text { Total saham yang dipegang institusi }}{\text { Total saham }}
$$

b. Kepemilikan asing pada perusahaan cenderung secara sukarela mengungkapkan informasi untuk mengurangi informasi asimetris yang terjadi antara manajemen dan pemegang saham. Menurut Barako et al. (2006), cara pengukuran kepemilikan asing adalah sebagai berikut:

$$
\begin{aligned}
& \text { Kepemilikan } \\
& \text { Asing }
\end{aligned}=\frac{\text { Total saham yang dipegang institusi/perorangan asing }}{\text { Total saham }}
$$

c. Kepemilikan manajerial dimana manajemen yang memiliki saham di perusahaan akan merasakan rasa memiliki terhadap perusahaan sehingga mendorong nilai perusahaan dimana bisa meningkatkan nilai pemegang saham. Menurut, Chakroun dan Matoussi (2012), cara pengukuran kepemilikan manajerial adalah sebagai berikut:

$$
\begin{aligned}
& \text { Kepemilikan } \\
& \text { Manajerial }
\end{aligned}=\frac{\text { Total saham yang dipegang pihak manajemen }}{\text { Total saham }}
$$

d. Ukuran dewan yang semakin besar berperan penting dalam pengawasan anggota dewan dan pembuatan keputusan. Ukuran dewan yang semakin besar tidak dominan dengan pihak manajemen sehingga akan mengungkapkan informasi secara lengkap kepada pemegang saham. Menurut Akhtaruddin et al. (2009), cara pengukuran ukuran dewan adalah sebagai berikut:

$$
\text { Ukuran Dewan }=\text { Jumlah anggota direksi }
$$

e. Komisaris independen dapat meningkatkan kualitas pelaporan perusahaan, Chau dan Leung (2006), menyatakan bahwa dengan adanya komisaris independen pada anggota dewan akan meningkatkan pengawasan terhadap manajemen perusahaan. Menurut Wu, Sorensen, dan Sun (2019), komisaris independen pada perusahaan keluarga dapat mengurangi asimetris informasi dibanding pada perusahaan non-keluarga. Menurut Barako (2007), cara pengukuran komisaris independen adalah sebagai berikut:

$$
\begin{aligned}
& \text { Komisaris } \\
& \text { independen }
\end{aligned} \quad=\frac{\text { Jumlah komisaris independen }}{\text { Jumlah anggota komisaris }}
$$

f. Komite audit mengawasi pelaporan informasi perusahaan sehingga menjadi terpercaya. Pelaporan berkurang kesalahan dan patuh pada peraturan karena komite audit memastikan pelaporan yang relevan (Rouf, 2011). Menurut Rouf et al. (2014), cara pengukuran komite audit adalah:

Komite Audit $=$ Jumlah anggota komite audit 
Variabel kontrol pada penelitian ini adalah ukuran perusahaan, leverage, dan profitabilitas.

a. Untuk mengurangi biaya agensi, perusahaan besar akan mengungkapkan informasi lebih daripada perusahaan kecil (Jensen \& Meckling, 1976). Menurut Hailin dan Zezhen (2008), cara pengukuran ukuran perusahaan adalah sebagai berikut:

Ukuran perusahaan $\quad=\quad \log$ (jumlah aset)

b. Tingkat leverage menunjukkan kemampuan perusahaan dalam membayar utang sehingga leverage mempengaruhi pengungkapan informasi agar investor mengetahui bahwa perusahaan mampu membayar utang kepada kreditur. Menurut Uyar et al. (2013), cara pengukuran leverage adalah:

$$
\text { Leverage } \quad=\frac{\text { Total utang }}{\text { Total aset }}
$$

c. Profitabilitas menunjukkan kemampuan perusahaan dalam menghasilkan keuntungan dengan aset atau ekuitas yang dimiliki oleh perusahaan. Menurut Darmadi dan Sodikin (2013), cara pengukuran profitabilitas adalah sebagai berikut:

$$
\text { Profitabilitas }=\frac{\text { Laba bersih }}{\text { Total aset }}
$$

Sesuai dengan tujuan penelitian, metode analisis data yang akan digunakan adalah analisis regresi panel karena penelitian bermaksud menyelidiki hubungan antara variabel independen dengan variabel depeden pada data longitudinal (gabungan antara data cross sectional dengan data time series). Aplikasi lunak yang akan digunakan adalah program Eviews 7 serta Statistical Package for the Social Sciences (SPSS) 21. Langkah-langkah analisis data meliputi uji statistika deskriptif, uji outlier, pemilihan model terbaik dengan uji chow (PLS vs FEM) dan uji hausman (FEM vs REM), uji F, uji t dan pengukuran goodness of fit model.

\section{HASIL PENELITIAN}

Data yang digunakan dalam penelitian ini berbentuk data sekunder. Objek penelitian ini adalah laporan keuangan tahunan perusahaan yang terdaftar di Bursa Efek Indonesia pada periode 2010 sampai dengan 2014. Informasi mengenai jumlah seluruh perusahaan disajikan pada Tabel 1 di bawah ini:

Tabel 1. Daftar Jumlah Perusahaan yang Dijadikan Sampel

\begin{tabular}{ll}
\hline Keterangan & Jumlah \\
\hline Perusahaan yang dijadikan sampel & 125 perusahaan \\
Tahun penelitian & 5 tahun \\
Jumlah data sampel & 625 data \\
Jumlah data outlier & (63 data) \\
Jumlah data pengujian & 562 data \\
\hline
\end{tabular}

Sumber: data diolah, 2016. 
Tabel 2. Hasil Uji Statistik Deskriptif

\begin{tabular}{llllll}
\hline Variabel & N & $\begin{array}{l}\text { Rata- } \\
\text { Rata }\end{array}$ & Std.Deviasi & Minimum & Maksimum \\
\hline $\begin{array}{l}\text { Pengungkapan } \\
\text { Sukarela }\end{array}$ & 562 & 0,65425 & 0,02491 & 0,59091 & 0,70455 \\
$\begin{array}{l}\text { Kepemilikan } \\
\text { Institusional }\end{array}$ & 562 & 0,67621 & 0,19220 & 0,00000 & 0,98966 \\
$\begin{array}{l}\text { Kepemilikan Asing } \\
\text { Kepemilikan }\end{array}$ & 562 & 0,10809 & 0,16489 & 0,00000 & 0,66928 \\
Manajerial & 562 & 0,03206 & 0,08952 & 0,00000 & 0,70003 \\
Ukuran Dewan & 562 & 4,79000 & 2,11800 & 2,00000 & 11,00000 \\
Komisaris & 562 & 0,40795 & 0,11258 & 0,14286 & 1,00000 \\
Independen & 562 & 3,02000 & 0,36300 & 0,00000 & 5,00000 \\
Komite Audit & 562 & $5.283,87$ & $13.014,99$ & 8,82 & $187.192,11$ \\
Ukuran Perusahaan \\
(miliar)
\end{tabular}

Sumber: data diolah, 2016.

Pada Tabel 2 menunjukkan hasil uji deskriptif pada perusahaan keluarga yang terdaftar di BEI, kepemilikan institusional memiliki nilai rata-rata $67 \%$ dimana lebih tinggi daripada kepemilikan lainnya menunjukkan pemegang saham dominan adalah pemegang saham institusi. Kepemilikan asing menduduki nilai rata-rata $10 \%$ pada urutan kedua kemudian kepemilikan manajerial 3,2\% pada urutan ketiga.

Rata-rata nilai ukuran dewan adalah 4 orang artinya setiap perusahaan memiliki rata-rata dewan direksi sebanyak 4 orang. Rata-rata persentase komisaris independen adalah $40 \%$. Hal ini menunjukkan bahwa secara rata-rata perusahaan keluarga pada BEI telah mengikuti pedoman BAPEPAM-LK bahwa perusahaan publik wajib memiliki minimal empat anggota dewan (UU NO. 40 Tahun 2007) dan memiliki sekurangkurangnya 30\% dari jajaran anggota dewan komisaris adalah komisaris independen (Pedoman tentang Komisaris Independen, 2004). Rata-rata jumlah anggota komite audit adalah 3 orang. Hal ini menunjukkan bahwa rata-rata ukuran komite audit di perusahaan Indonesia telah memenuhi ketentuan BAPEPAM dalam KEP-339/BEJ/07-2001 bahwa jumlah komite audit minimal 3 orang.

Sumber pendanaan pada perusahaan keluarga di Bursa Efek Indonesia rata-rata berasal dari utang yaitu sebesar $57,27 \%$ dari total aset. Variabel ukuran perusahaan pada perusahaan keluarga yang terdaftar di Bursa Efek Indonesia rata-rata memiliki aset senilai Rp 5.283.000.000.000,00. Hal ini menunjukkan bahwa perusahaan keluarga di Indonesia tergolong besar karena melebihi persyaratan perusahaan tercatat di BEI dengan nilai aktiva bersih lebih dari 100 (milyar rupiah). Tingkat profitabilitas pada perusahaan keluarga cenderung memiliki penyebaran yang tinggi dan rata-rata perusahaan memiliki tingkat profit yang rendah yakni 5\% dari total aset perusahaan.

Pengujian outlier menggunakan pengukuran Studentized Deleted Residual (SDR). Hasil uji outlier dengan sampel perusahaan keluarga terdapat 63 data outlier sehingga sisa data yang akan diuji sebanyak 562 data dapat dilihat pada Tabel 1. 
Uji Chow digunakan untuk memilih metode antara PLS dan FEM. Kriteria yang digunakan dalam pemilihan metode adalah nilai probabilitas pada Cross-Section Chisquare pada hasil uji Chow apabila nilai probabilitas diatas 0,05, maka akan ditentukan metode yang akan digunakan pada penelitian ini adalah PLS tetapi apabila nilai probabilitas dibawah 0,05 maka akan dilanjutkan dengan uji Hausman. . Berdasarkan Tabel 3, pengujian pada sampel perusahaan keluarga menunjukkan hasil probabilitas Cross-Section Chi-square dibawah nilai 0,05 sehingga akan dilanjutkan uji Hausman untuk menentukan metode yang terbaik.

Tabel 3. Hasil Uji Chow

\begin{tabular}{l|l|}
\hline \multirow{2}{*}{ Effects Test } & \\
\cline { 2 - 2 } & Prob. \\
\hline Cross-section F & 0,0000 \\
Cross-section Chi-square & 0,0000 \\
\hline
\end{tabular}

Sumber: data diolah, 2016.

Uji Hausman digunakan untuk memilih metode antara FEM dan REM. Kriteria yang digunakan dalam pemilihan metode adalah nilai probabilitas pada cross-section random pada hasil uji Hausman apabila nilai probabilitas diatas 0,05, maka akan ditentukan metode yang akan digunakan pada penelitian ini adalah REM tetapi apabila nilai probabilitas dibawah 0,05 maka akan menggunakan metode FEM. Berdasarkan hasil uji hausman, pengujian menggunakan metode FEM disebabkan nilai probabilitas dibawah 0,05 .

Tabel 4. Hasil Uji Hausman

\begin{tabular}{l|l|}
\hline Test Summary & \\
\cline { 2 - 2 } & Prob. \\
\hline Cross-section random & 0,0001 \\
\hline
\end{tabular}

Sumber: data diolah, 2016.

Uji F dilakukan dengan tujuan untuk mengetahui pengaruh variabel independen terhadap variabel dependen secara silmutan. Kesimpulan dari hasil uji F pada penelitian ini adalah model regresi dapat digunakan untuk memprediksi faktor yang mempengaruhi pengungkapan sukarela.

Tabel 5. Hasil Uji F

\begin{tabular}{l|l|}
\hline $\mathrm{F}$ & 6,284808 \\
\hline Significant & 0,000000 \\
\hline
\end{tabular}

Sumber: data diolah, 2016.

Hasil uji $\mathrm{t}$ digunakan untuk mengetahui pengaruh masing-masing variabel independen terhadap variabel dependen yang ditunjukkan pada Tabel 6. Hasil penelitian menunjukkan bahwa pada perusahaan keluarga, kepemilikan selain keluarga seperti kepemilikan institusional, kepemilikan asing, dan kepemilikan manajerial tidak memiliki 
pengaruh signifikan terhadap pengungkapan informasi secara sukarela. pemegang saham luar dengan mengungkapkan informasi sebanyak mungkin. Hasil penelitian juga menujukkan variabel ukuran dewan dan variabel komite audit memiliki pengaruh signifikan positif terhadap pengungkapan sukarela, dimana berarti dewan dan komite audit pada perusahaan keluarga melaksanakan tanggung jawab mereka sebagaimana mestinya. Hasil penelitian menunjukkan komisaris independen tidak signifikan berpengaruh terhadap pengungkapan sukarela.

Tabel 6. Hasil Uji t

\begin{tabular}{|c|c|c|c|c|}
\hline \multirow{2}{*}{ Variabel } & \multicolumn{4}{|c|}{ Perusahaan Keluarga (Fixed) } \\
\hline & b & $\mathbf{t}$ & Sig & Hasil \\
\hline $\mathrm{C}$ & 0.5356 & 17.693 & 0.0000 & \\
\hline $\begin{array}{l}\text { Kepemilikan } \\
\text { Institusional }\end{array}$ & $\begin{array}{l}- \\
0.0072\end{array}$ & $\begin{array}{l}- \\
0.8135\end{array}$ & 0.2082 & tidak Sig. \\
\hline Kepemilikan Asing & $-\overline{0}-0063$ & $\begin{array}{l}- \\
0.6554\end{array}$ & 0.2563 & tidak Sig. \\
\hline Kepemilikan Manajerial & 0.0005 & 0.0284 & 0.4887 & tidak Sig. \\
\hline Ukuran Dewan & 0.0017 & 1.9914 & 0.0236 & Sig. positif \\
\hline Komisaris Independen & $\begin{array}{l}- \\
0.0004\end{array}$ & $\begin{array}{l}- \\
0.0374\end{array}$ & 0.4851 & tidak Sig. \\
\hline Komite Audit & 0.0058 & 1.7188 & 0.0432 & Sig. positif \\
\hline Ukuran Perusahaan & 0.0083 & 3.5012 & 0.0003 & Sig. positif \\
\hline Leverage & 0.0021 & 1.1142 & 0.1329 & tidak Sig. \\
\hline Profitabilitas & 0.0253 & 2.2274 & 0.0132 & Sig. positif \\
\hline
\end{tabular}

Sumber: data diolah, 2016.

Hasil uji adjusted $\mathrm{R}^{2}$ ini dilakukan untuk menguji persentase kecocokan model yaitu pengaruh kepemilikan institusional, kepemilikan asing, kepemilikan manajerial, komite audit, ukuran dewan, dan komisaris independen terhadap pengungkapan sukarela. Pada Tabel 7, hasil penelitian menunjukkan kepemilikan institusional, kepemilikan asing, kepemilikan manajerial, komite audit, ukuran dewan, dan komisaris independen dapat menjelaskan variabel pengungkapan sukarela sebesar 53,27\% sedangkan 46,73\% dijelaskan oleh faktor lain atau variabel independen lain yang tidak terdapat di model.

Tabel 7. Hasil Uji R Square

\begin{tabular}{l|l|}
\hline & $\begin{array}{l}\text { Pengungkapan } \\
\text { Sukarela }\end{array}$ \\
\hline $\mathbf{R}^{\mathbf{2}}$ & $63,34 \%$ \\
Adjusted $\mathbf{R}^{\mathbf{2}}$ & $53,27 \%$ \\
\hline \hline
\end{tabular}

Sumber: data diolah, 2016.

\section{KESIMPULAN}

Berdasarkan hasil analisis dan pembahasan yang telah dilakukan maka dapat disimpulkan bahwa pengungkapan sukarela pada perusahaan keluarga dominan 
dipengaruhi oleh kepemilikan keluarga, disebabkan kepemilikan selain keluarga, seperti kepemilikan institusional, kepemilikan asing, dan kepemilikan manajerial tidak memiliki pengaruh signifikan terhadap pengungkapan sukarela. Ukuran dewan dan komite audit memiliki pengaruh signifikan terhadap pengungkapan sukarela pada perusahaan keluarga, sedangkan komisaris independen tidak memiliki pengaruh signifikan. Variabel kontrol seperti ukuran perusahaan dan profitabilitas menjadi sebuah timbangan dalam perusahaan keluarga ketika ingin mengungkapkan informasi secara sukarela. Penelitian ini penting bagi perusahaan dan pemegang saham di Indonesia. Penelitian ini memberikan sebuah gambaran mengenai konflik yang dapat terjadi pada perusahaan selain daripada konflik keagenan antara manajemen dan pemegang saham juga adanya konflik antara pemegang saham mayoritas dan pemegang saham minoritas. Penelitian ini memberikan implikasi manajerial kepada para investor dimana hasil penelitian menunjukkan perusahaan yang dikontrol oleh anggota keluarga menghambat pengungkapan informasi yang dilakukan perusahaan. Hal ini menunjukkan bahwa investor pada perusahaan keluarga harus mengawasi indeks pengungkapan sukarela agar tidak terdapat pengungkapan informasi yang merugikan para investor.

\section{DAFTAR PUSTAKA}

Akhtaruddin, M., Hossain, M. A., Hossain, M., \& Yao, L. (2009). Corporate governance and voluntary disclosure in corporate annual reports of Malaysian listed firms. JAMAR, (7).

Alhazaimeh, A., Palaniappan, R., \& Almsafir, M. (2014). The Impact of Corporate Governance and Ownership Structure on Voluntary Disclosure in Annual Reports among Listed Jordanian Companies. Procedia-Social and Behavioral Sciences, 129, pp. 341-348.

BAPEPAM (2001). Keputusan Ketua Badan Pengawas Pasar Modal Nomor: KEP339/BEJ/07-2001.

BAPEPAM (2012). Keputusan Ketua Badan Pengawas Pasar Modal Nomor: KEP431/BL/2012.

Barako, D. G., Hancock, P., \& Izan, H. Y. (2006). Relationship between corporate governance attributes and voluntary disclosures in annual reports: the Kenyan experience. Financial Reporting, Regulation and Governance, 5(1).

Barako, D. G. (2007). Determinants of voluntary disclosures in Kenyan companies annual reports. African Journal of Business Management, 1 (5), pp. 113-128.

Bushman, R., Chen. Q., Engel, E., \& Smith, A. (2004). Financial accounting information, organizational complexity and corporate governance systems. Journal of Accounting and Economics, 37, pp. 167-201.

Chakroun, R. \& Matoussi, H. (2012). Determinants of the extent of voluntary disclosure in the annual reports of the Tunisian firms. Accounting and Management Information Systems, 11(3), pp. 335-370.

Chau, G. \& Leung, P. (2006). The impact of board composition and family ownership on audit committee formation: evidence from Hong Kong. Journal of International Accounting, Auditing and Taxation, 15, pp. 1-15.

Chen, C. J. P. \& Jaggi, B. (2000). Association between independent non-executive directors, family control and financial disclosures in Hong Kong. Journal of Accounting and Public Policy, 19(4-5), pp. 285-310. 
Claessens, S., Djankov, S., \& Lang, L. H. P. (2000). The separation of ownership and control in East Asian corporations. Journal of Financial Economics, 58(1-2), pp. 81-112.

Darmadi, S. \& Sodikin, A. (2013). Information disclosure by family-controlled firms. Asian Review of Accounting, 21(3), pp.223-240.

Dominiquez, L. R. \& Gamez, L. C. N. (2013). Corporate reporting on risks: Evidence from Spanish companies. Spanish Accounting Review, 17(2), pp.116-129.

Financial Accounting Standard Board. (2000). www.fasb.org.

Haely, P. M. \& Palepu, K. G. (2001). Information asymmetry, corporate disclosure, and the capital markets: a review of the empirical disclosure literature. Journal of Accounting and Economics, (35), 1-3, pp. 405-440.

Hailin, W. \& Zezhen, M. (2008). Analysis on impact of corporate governance to voluntary disclosure-based on the empirical data of real estate industry. Orient Academic Forum.

Haniffa, R. M. \& Cooke, T. E. (2002). Culture, corporate governance and disclosure in Malaysian corporations. Abacus, (38), 3, pp. 317-349.

Hassan, M. K. (2013). Corporate governance characteristics and voluntary disclosure: the case of UAE listed corporation. International Conference on Business Economics, and Accounting 20-23 March 2013, Bangkok-Thailand.

Huang, X. \& Kang, F. (2019). Are family firms more optimistic than non-family firms?. Accounting Research Journal, (32), 2, pp. 399-416.

Hossain, M. \& Hammami, H. (2009). Voluntary disclosure in the annual reports of an emerging country: the case of Qatar. Advances in Accounting, incorporating Advances in International Accounting, 25, pp. 255-265.

Ho, S. \& Wong, K. S. (2001). A study of The Relationship between Corporate Governance Structures and the Extent of Voluntary Disclosure. Journal of International Accounting, Auditing \& Taxation,(10), 2, pp. 139-156.

Indriantoro, N., \& Supomo, B. (2013). Metodologi Penelitian Bisnis untuk Akuntansi dan Manajemen. Yogyakarta.

Jensen, M. C., \& Meckling. (1976). Theory of The Firm: Managerial Behavior, Agency Costs and Ownership Structure. Journal of Financial Economics, 3, 305-360.

Kateb, I. (2012). An analysis of the determinants of voluntary structural capital disclosure by listed French companies. International Journal of Business and Management, (7), 11, pp. 95-110.

La Porta, R., Silanez, L. D., \& Shleifer, A. (1999). Corporate ownership around the world. The Journal of Finance, 54(2), pp. 471-517.

Levitt, A. (2000). Renewing the Covenant with Investors. Speech at New York University Center for Law and Business. http://www.sec.gov/news/ speeches/spch370.htm

Louie, J., Ahmed, K., \& Ji, D. (2019) Voluntary disclosures practices of family firms in Australia. Accounting Research Journal, (32), 2, pp. 273-294.

Meek, G. K., Roberts, C. B., \& Gray, S. J. (1995). Factors influencing voluntary annual report disclosures by US, UK and continental European multinational corporations. Journal of International Business Studies, (26), 3, pp: 555-572.

Nandi, S. \& Ghosh, S. K. (2012). Corporate governance attributes, firm characteristics and the level of corporate disclosure: Evidence from the Indian listed firms. Decision Science Letters 2, pp. 45-58. 
Percy, M. (2000). Financial reporting discretion and voluntary disclosure: corporate research and development expenditure in Australia. Asia-Pacific Journal of Accounting \& Economics, 7(1), pp. 1-31.

PricewaterhouseCooper (PWC). (2014). Survey Bisnis Keluarga 2014. www.pwc.com/id.

Rouf, A. (2011). Corporate characteristics, governance attributes and the extent of voluntary disclosure in Bangladesh. African Journal of Business Management, 5(19), pp. 7836-7845.

Rouf, M. A. \& Harun, M. A. (2011). Ownership structure and voluntary disclosure in annual reports of Bangladesh. Pak. J. Commer. Soc. Sci, (5), 1, pp. 129-139.

Rouf, M. A., Hasan, M. S., \& Ahmed, A. A. (2014). Financial reporting practices in the textile manufacturing sectors of Bangladesh. ABC Jorunal of Advanced Research, 3(2), pp. 57-67.

Surat Keputusan Menteri Badan Usaha Milik Negara. (2002). Penerapan praktek good corporate governance pada Badan Usaha Milik Negara (BUMN). KEP-117/MMBU/2002.

Undang-Undang Republik Indonesia No. 40 Tahun 2007 Tentang Perseroan Terbatas. Indonesia.

Uyar, A., Kilic, C., \& Bayyurt, N. (2013). Association between firm characteristics and corporate voluntary disclosure: Evidence from Turkish listed companies. Intangible Capital, 9(4), pp. 1068-1112

Vural, D (2018). Disclosure practives by family firms: evidence from Swedish publicly listed firms, Accounting in Europe, 1-27.

Wang, H. \& Zezhen, M. (2011). Analysis on impact of corporate governance to voluntary disclosures- based on the empirical data of Chinese real estate industry. Accounting School, Capital University of Economy and Business, Beijing, P.R.China.

$\mathrm{Wu}, \mathrm{K}$. , Sorensen, S., \& Sun, L. (2019). Board independece and information asymmetry: family firms vs non-family firms. Asian review of accounting, vol. 27, no.3, pp.329349.

Zanani, W. A., Shahanaz, I., \& Nurasyikan, J. N. (2008). The impact of board size, ownership, and CEO duality on audit quality: the Malaysian evidence. Malaysian Accounting Review, (7), 2, pp. 17-28. 